\title{
Impacts of Niche Breadth and Dispersal Ability on Macroevolutionary Patterns
}

\author{
Huijie Qiao, ${ }^{1}$ Erin E. Saupe, ${ }^{2, *}$ Jorge Soberón, ${ }^{3}$ A. Townsend Peterson, ${ }^{3}$ and Corinne E. Myers ${ }^{4, \dagger}$ \\ 1. Institute of Zoology, Chinese Academy of Sciences, 1 Beichen West Road, Chaoyang District, Beijing 100101, People's Republic of China; \\ 2. Yale University, 210 Whitney Avenue, New Haven, Connecticut 06511; 3. Biodiversity Institute, University of Kansas, 1345 Jayhawk \\ Boulevard, Lawrence, Kansas 66045; 4. Harvard University, 26 Oxford Street, Cambridge, Massachusetts 02138; and University of \\ New Mexico, Northrop Hall, Albuquerque, New Mexico 87131
}

Submitted August 20, 2015; Accepted March 29, 2016; Electronically published May 31, 2016

Online enhancements: appendix, video, Excel file.

\begin{abstract}
AвSTRACT: We describe a spatially explicit simulation experiment designed to assess relative impacts of macroecological traits on patterns of biological diversification under changing environmental conditions. Using a simulation framework, we assessed impacts of species' niche breadth (i.e., the range of their abiotic tolerances) and dispersal ability on resulting patterns of speciation and extinction and evaluated how these traits, in conjunction with environmental change, shape biological diversification. Simulation results supported both niche breadth and dispersal ability as important drivers of diversification in the face of environmental change, and suggested that the rate of environmental change influences how species interact with the extrinsic environment to generate diversity. Niche breadth had greater effects on speciation and extinction than dispersal ability when climate changed rapidly, whereas dispersal ability effects were elevated when climate changed slowly. Our simulations provide a bottom-up perspective on the generation and maintenance of diversity under climate change, offering a better understanding of potential interactions between species' intrinsic macroecological characteristics and a dynamic extrinsic environment in the process of biological diversification.
\end{abstract}

Keywords: cellular automaton algorithm, climate change, diversification rates, Eurasia, extinction, speciation, simulation.

\section{Introduction}

Over its 4.6-billion-year history, Earth has experienced significant environmental changes that have varied in both rate and periodicity. How these changes have influenced macroevolutionary trajectories in the context of specific macroecological traits remains a long-standing question in evolutionary biology (Vrba 1985; Allmon and Ross 1990; Diniz-Filho and Tôrres 2002; Eldredge 2003; Rothschild and Lister 2003; Lieberman 2005; Colwell and Rangel 2010; Eastman and Storfer 2011; Myers and Saupe 2013; Svenning et al. 2015).

* Corresponding author; e-mail: eesaupe@gmail.com.

† ORCIDs: Soberón, http://orcid.org/0000-0003-2160-4148.

Am. Nat. 2016. Vol. 188, pp. 149-162. (C) 2016 by The University of Chicago. 0003-0147/2016/18802-56477\$15.00. All rights reserved.

DOI: $10.1086 / 687201$
Previous investigations have focused on the roles of geographic range size (Gaston 2003; Harris and Pimm 2008; Jablonski 2008; Harnik 2011), dispersal ability (Jablonski 1986; Lieberman et al. 1993; Kisel and Barraclough 2010; Salisbury et al. 2012), and environmental tolerance (Allmon and Ross 1990; Colwell and Rangel 2010; Myers and Saupe 2013), among others, in influencing patterns of speciation and extinction.

Such investigations have shaped views on how evolution proceeds significantly, resulting, for example, in the formulation of the cradle and museum hypotheses regarding whether higher diversity in the tropics is structured by elevated speciation rates or dampened extinction rates, respectively (Chown and Gaston 2000; Wiens and Donoghue 2004). Additional research, however, is required to understand how extinction and speciation interact in time and space to yield observed patterns, given the complexity of disentangling interactions among factors that affect diversification, such as the size of species' distributional area relative to the shape and extent of the continents, the location of barriers, and the dynamics of temporal change (Chown and Gaston 2000).

While interesting from the perspective of evolutionary theory, such investigations are also highly relevant to issues of conservation and sustainability, given that Earth's climate system is currently experiencing significant change that is affecting diversity on global scales (Pachauri et al. 2014). Indeed, the environmental changes that produced historical mass extinctions and spawned later diversification and wholesale ecological change are predicted to occur today over only $\sim 10^{2}$ years, as compared with the $10^{3}$ - to $10^{6}$-year timescales of past major events (Barnosky et al. 2011; Pimm et al. 2014). As such, understanding how a dynamic environment shapes diversity has never been more pressing.

Here, we use spatially explicit simulation experiments to assess the relative impacts of two key macroecological traits on diversification under changing environmental con- 
ditions. The intent of these simulations is to generate suites of expectations regarding the relative importance of macroecological traits in driving diversification. We further investigate whether the relative importance of such traits differs depending on the rate of environmental change. This is achieved using a simple system that controls for potential confounding factors (e.g., niche evolution, species interactions). We focus on two specific traits: breadth of species' abiotic tolerances and dispersal ability. These traits - in conjunction with biotic interactions - have been identified as key factors controlling species' distributions across geographic landscapes (Soberón and Peterson 2005; Peterson et al. 2011). Biotic interactions were not considered in the present analyses; they are highly complex and difficult to model (Wisz et al. 2013), and they often operate at finer spatiotemporal scales than the continental spatial scale and thousand-year timescale explored here (Soberón 2010; but see Bullock et al. 2000). Our goal is to simplify reality to a core suite of causal factors that potentially influence diversification (Rangel et al. 2007; Soberón 2007, 2010; Gotelli et al. 2009; Saupe et al. 2012).

A simulation approach is particularly informative for elucidating impacts of species' macroecological traits on macroevolutionary patterns because traits can be held constant and their effects and interactions observed directly (Rangel et al. 2007; Escarguel et al. 2008; Gotelli et al. 2009). Such ecological experiments allow for deduction of testable predictions regarding how the world would function if a set of simplifying assumptions were to hold. That is, the simulations presented here track macroevolutionary dynamics of simplified species and environments: no trait evolution or interaction between species occurs, climate change is periodic and predictable, and species' abiotic tolerances are manifested in only two dimensions. Additionally, only a few representative classes were considered for species' dispersal abilities (poor and good) and niche breadths (narrow, intermediate, and broad), whereas these traits certainly vary more widely among real species.

Although we invoke a series of simplifying assumptions, they are based on previous research and ecological theory, and we rely on empirical data to inform niche breadths, dispersal abilities, and climatic extremes. Thus, the value of this admittedly simplistic scheme lies in its ability to compare and contrast empirically grounded scenarios and observe their effects on diversity patterns. Of course, our simulations may not capture all aspects of biological reality, but this feature was purposeful so as to isolate interactions between specific macroecological traits and climate change in affecting speciation and extinction rates.

Via our simulation framework, we investigated the predictions that niche breadth impacts rates of speciation and extinction and that dispersal ability is important only to the degree that it covaries with niche breadth. We predicted a primary role for species' abiotic requirements in affecting speciation and extinction rates, since this trait determines the amount and structure of suitable area that a species can occupy and how this area changes as the environment fluctuates (e.g., a specialist species may experience more volatility in the amount and structure of suitable habitat than a generalist species). Previous work has shown that degree of specialization is often positively correlated with speciation and extinction potential (Eldredge 1979, 1989; Vrba 1980; Stanley 1990; Kammer et al. 1997, 1998; Nürnberg and Aberhan 2013; Saupe et al. 2015): specialist species are more likely to form isolated populations during times of environmental change, increasing opportunities for allopatric speciation (but see Fisher-Reid et al. 2012). Similarly, niche breadth is expected to correlate negatively with extinction rates, as environmental change is more likely to remove all suitable habitat (leading to extinction) for narrow-tolerance species.

We posit a secondary role for dispersal ability, which in this formulation affects how species are able to move within a landscape to reach suitable habitat and avoid or traverse unsuitable areas. We envision a secondary role for dispersal because previous research suggests that this trait may not play as strong of a role in structuring species' geographic distributions as niche dimensions (Gilbert and Lechowicz 2004; Lester et al. 2007). Dispersal ability has been found to correlate negatively with speciation and extinction potential because species with greater dispersal ability experience less range restriction and are more likely to detect and colonize newly suitable areas (Shuto 1974; Hansen 1980; Jablonski 1986; Palumbi 1994; Dieckmann et al. 1999; Allen and Gillooly 2006; Roy and Goldberg 2007; Kisel and Barraclough 2010; Knowles and Alvarado-Serrano 2010; Dobrovolski et al. 2012; Salisbury et al. 2012; Linder et al. 2014). Although dispersal ability is difficult to quantify in the fossil record, this relationship has been observed in studies of marine gastropods, where taxa with planktonic larvae and inferred high dispersal ability show lower rates of speciation and extinction compared to those with benthic larvae and inferred low dispersal ability (Hansen 1983; Jablonski 1986; Lieberman et al. 1993; Gili and Martinell 1994).

In this article, we present detailed comparisons and contrasts of the relative roles of niche breadth and dispersal in driving speciation and extinction within the context of a dynamic climate system. Although a robust body of literature supports a role for both dispersal and niche breadth (Kammer et al. 1998; Allen and Gillooly 2006; Kisel and Barraclough 2010; Dobrovolski et al. 2012; Nürnberg and Aberhan 2013), few studies test explicitly how these traits act and interact to shape speciation and extinction potential under changing environmental conditions. We examine how dispersal ability and niche breadth influence rates of speciation and extinction under three climate-change scenarios to assess whether patterns are congruent across different rates 
and periodicities of environmental change. Following Rangel et al. (2007), we predicted that these climate scenarios would not affect the mode of diversification but only the tempo or magnitude of the diversity produced, that is, that different styles of climate change may increase or decrease numbers of speciation and extinction events observed but would not influence how macroecological traits interact with climate to produce that diversity. A simulation-based study allows us to disentangle the relative roles of these traits on macroevolutionary dynamics in a controlled and quantitative analytical environment. Thus, we provide a bottom-up perspective on the generation of diversity within a dynamic climate system.

\section{Methods}

\section{Model Overview}

We use a cellular automaton algorithm (Grimm et al. 2005; Hooten and Wikle 2010). Our model simulates state changes of cells (i.e., occupied vs. empty) in a gridded world in which cell occupation is controlled by species' abiotic tolerances and dispersal abilities in relation to the environmental conditions manifested in that cell. Climatic attributes of each cell fluctuate and may be favorable or unfavorable for a species at a given time depending on whether they fall within its niche. This model combines different niche requirements with different dispersal capabilities to assess how contrasting niche breadths and dispersal abilities impact rates of speciation and extinction under climate change, given our model assumptions. Within the simulation, species are always exploring geographic space by dispersing and colonizing new areas, responding to changing environmental conditions that expand or contract species' geographic potential. Such changes can initiate speciation by fragmenting ranges via isolation of suitable areas and/or trigger extinction by eliminating all suitable areas.

Similar to Rangel et al. (2007), our simulations link a gridded geographic domain with a two-dimensional environmental landscape. The geographic component of the model is a $0.5^{\circ} \times 0.5^{\circ}$ grid covering Eurasia (58,745 grid cells; fig. 1). Each grid cell corresponds to a pair of environmental values (annual mean temperature and annual mean precipitation). Thus, the environmental data are spatially explicit and capture empirical patterns of climatic heterogeneity across Eurasia. Conditions vary from warm to cold in accordance with climate variation, as simulated in the Community Climate System Model (CCSM4) under the CMIP5 multimodel ensemble for the mid-Holocene Warm Period $(\sim 6 \mathrm{Ka})$ and Last Glacial Maximum (LGM; $25 \mathrm{Ka}$; data from WorldClim; Hijmans et al. 2005; fig. 2). Time is recorded in model steps, which are roughly equivalent to years; speciation and extinction data are captured every 500 model steps (i.e., every 500 years).
Species colonize geographic areas across Eurasia based on sites of origin randomly seeded across Eurasia (described below) and their assigned niche breadth and dispersal ability. In environmental space, niches are characterized by twodimensional rectangles, within which all conditions are considered suitable (fig. A1; figs. A1, A2 available online). These climatic envelopes represent species' fundamental niches (FNs) in the classic sense of Hutchinson (1957). Once positioned on the landscape, representation of a species' FN is limited by environmental combinations existing and accessible at a given time step, which is referred to as the existing or potential ecological niche (Jackson and Overpeck 2000; Peterson et al. 2011).

The dimensions of each FN rectangle are derived from empirical temperature and precipitation tolerances of agriculturally important plant species (Food and Agriculture Organization of the United Nations; see Hijmans et al. 2001). Given our interest in testing contrasting conditions, we focus on three niche-breadth definitions: narrow (specialist), intermediate, and broad (generalist). Distributions of niche dimensions are obtained by sorting the 1,710 species in the data set by breadth in terms of temperature and precipitation tolerances; exemplars are then chosen from each end and the center of the distribution. Purple veldtgrass (Ehrharta calycina) serves as the representative specialist species, with a breadth of $12^{\circ} \mathrm{C}$ for temperature and $150 \mathrm{~mm}$ for precipitation. Ambarella (Spondias dulcis) serves as the representative intermediate species, with a breadth of $23^{\circ} \mathrm{C} \times 1,600 \mathrm{~mm}$. Finally, the Java plum (Syzygium $\mathrm{cu}$ mini) is the representative generalist species, with a breadth of $35^{\circ} \mathrm{C} \times 9,100 \mathrm{~mm}$ (fig. A1).

Species are also assigned good or poor dispersal abilities, corresponding to search distances (i.e., potential dispersal) for habitable cells. Dispersal in this formulation represents the process of colonization and range expansion and differs from other definitions of dispersal at local scales (e.g., movement of individuals). Good dispersers may search for suitable habitat within a distance of five cells per 500 model steps, whereas poor dispersers may only search up to one cell in that same time. One and five cells correspond roughly to $50-\mathrm{km}$ and $250-\mathrm{km}$ search distances over 500 years, respectively, since a cell in our landscape is $0.5^{\circ}(\sim 50 \mathrm{~km})$, and model time steps are analogous to years. These distances are approximated from empirically derived seed-dispersal capacities in plants (Cain et al. 2000; Svenning and Sandel 2013) and follow the general migration criteria used by Rangel and Diniz-Filho (2005): minimum estimated migration rates for plants range from 0 to $20 \mathrm{~m} /$ year, which scales to $0-10 \mathrm{~km}$ in 500 years, whereas long-distance dispersal estimates range from 100 to $1,000 \mathrm{~m} /$ year, equivalent to $50-500 \mathrm{~km}$ in 500 years. Thus, a $\sim 250-\mathrm{km}$ dispersal distance for good dispersers is consistent with what is considered long distance. Poor dispersers are allowed to search farther than 


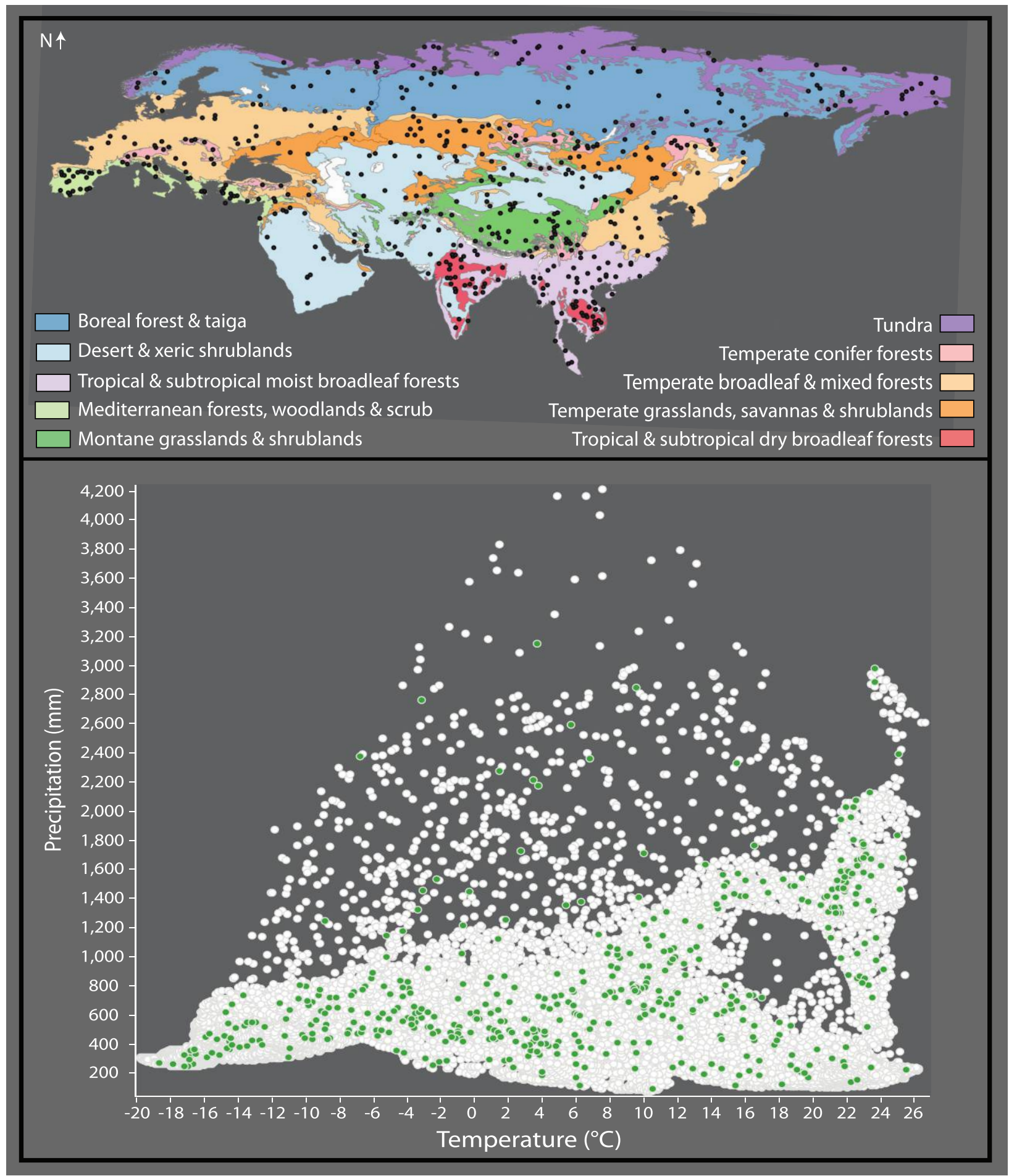

Figure 1: Seed points from which simulations were initiated in geographic (top) and environmental (bottom) spaces. Top, major biomes across Eurasia, as defined by the World Wildlife Fund, which were sampled randomly at comparable intensities. Regions in white are biomes not included owing to their small geographic extents. Bottom, representation of seed points (green) in the mid-Holocene mean annual environmental space (temperature $\times$ precipitation) of Eurasia. 


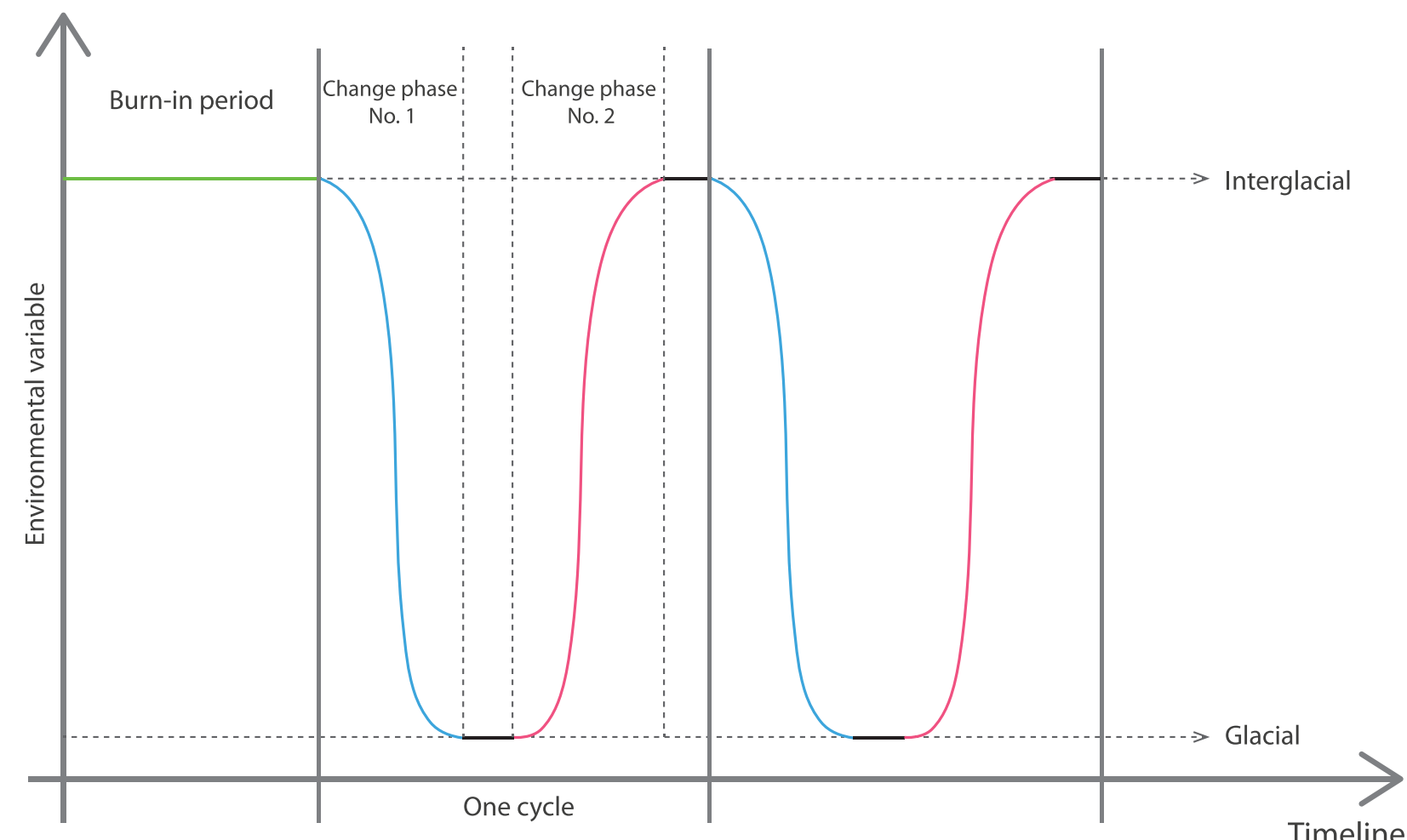

Figure 2: Climatic curve used to vary temperature and precipitation conditions. The $Y$-axis illustrates how climate characteristics were scaled from interglacial (mid-Holocene warm period) to glacial (Last Glacial Maximum) conditions, and the $X$-axis depicts time steps in the simulation. The stable portion of the curve at the beginning of the simulation represents the burn-in period, during which climate was held constant, and species were allowed to search for suitable habitat within their dispersal abilities. Each simulation was run for 150,000 time steps after the burn-in period of 50,000 time steps. This time period equates to 1.5 cycles under the slow scenario, 3 cycles under the moderate scenario, and 6 cycles under the rapid scenario.

minimum estimated migration rates $(10 \mathrm{~km})$ because the minimum resolvable distance of the spatial grid structure of our simulations is one $0.5^{\circ}$ cell $(\sim 50 \mathrm{~km})$.

Under these constraints, poor dispersers can search adjacent cells only, whereas good dispersers can jump over unsuitable patches to encounter more spatially remote but suitable cells (fig. A2). Species search for suitable cells simultaneously from all cells currently occupied. Distance is measured using Manhattan distances $(d)$, in which the distance traveled from one data point $\left(x_{i}, y_{i}\right)$ is the sum of absolute values of differences across both dimensions.

\section{Model Dynamics}

Species begin the simulation as a single cell chosen at random from within Eurasia under warm, mid-Holocene interglacial conditions. The temperature and precipitation values of the chosen cell define optimal environmental conditions for the species (i.e., the center of the FN). From these values, symmetrical deviations are applied following a process similar to that of Rangel et al. (2007) and based on the broad, intermediate, and narrow niche-breadth dimensions defined above. Species are then allowed to spread from this initial cell to search for suitable habitat within the range of their dispersal ability during a burn-in period of 50,000 model time steps (roughly equivalent to years), with climate constant at mid-Holocene conditions (fig. 2). Throughout all simulations, species immediately occupy any suitable cell that they encounter, until that cell becomes unsuitable due to climate change (Rangel et al. 2007; Gotelli et al. 2009). This process imitates natural range dynamics of species, which are thought to often begin small and expand rapidly (Webb and Gaston 2000; Liow and Stenseth 2007).

After burn-in, climate is modified in one of three ways, representing fast, moderate, and slow climate-change scenarios. Values for each grid cell vary according to a sine wave function oscillating between warm and cold conditions (sensu Rangel et al. 2007). A single climate cycle consists of one period of the sine function (fig. 2). The same function is applied to temperature and precipitation values synchronously, and both are interpolated between interglacial and glacial conditions (fig. 2). 
Environmental changes modify distributions of suitable cells uniquely for each species (i.e., dependent on niche dimensions); species track suitable cells through these changes as a function of their dispersal ability. One consequence of environmental change may be fragmentation of suitable areas, resulting in newly isolated populations (see video A1, available online, illustrating these processes). Speciation is defined allopatrically, given the apparent dominance of this speciation mechanism and our focus on a spatially explicit simulation of diversification (Mayr 1942; Barraclough and Vogler 2000; Turelli et al. 2001; Fitzpatrick et al. 2009; Wiley and Lieberman 2011; Edwards et al. 2012). Isolation in our landscape is a joint consequence of the topologies of both geographic and environmental spaces.

Populations experiencing isolation for 10,000 time steps (years) are treated as new lineages (species). Of course, longer or shorter times to speciation may impact model results (i.e., dampening or accelerating rates, respectively). However, 10,000 years corresponds roughly with what is considered reasonable speciation times, based on paleontological and neontological data (Lande 1980; Williamson 1981; Valentine 1985; Knowles 2000; Gould 2002; Johnson and Cicero 2004).

Upon origination, daughter species have identical niche breadth and dispersal ability as their parent species, following the assumption of no trait evolution. The lack of evolution in species' niche breadths and dispersal abilities invokes the fewest assumptions (regarding demographic processes, genetic/phenotypic plasticity, evolvability, etc.) and, although unrealistic on broad spatiotemporal scales, allows for the effects of these traits to be isolated more easily and provides a baseline model to which evolutionary change can later be added. In natural systems, niche breadth and dispersal ability will vary among species; how this may affect macroevolutionary dynamics is not treated here since our goal is to isolate potential interactions between macroecological traits and environmental change within a simplified system. Populations (collections of occupied cells) that separate and reemerge in less than 10,000 time steps are not regarded as distinct evolutionary lineages. Once produced, new offspring species immediately begin finding and occupying all suitable areas within their dispersal ability; that is, in the simulation, no biotic interactions exclude species from suitable areas or impact extinction dynamics.

Extinction occurs when all cells for a species become unsuitable or when all suitable cells are unreachable. This strict extinction criterion is used because it invokes the fewest assumptions and because we are cognizant of the relatively coarse spatial resolution of the simulation. That is, we apply no specific demographic model or inferred minimum population survivorship threshold. In each simulation (i.e., for every seed point), speciation and extinction events are documented and stored as phylogenetic trees.
These trees record relationships among ancestral and descendant species and provide timing of all speciation and extinction events.

\section{Simulations}

To account for vagaries in environmental heterogeneity, simulations were initiated from 500 seed points dispersed randomly across Eurasia and stratified across 10 major biomes (fig. 1). Each seed point was tested under all combinations of niche breadth, dispersal ability, and climate-change scenario. This replication resulted in a total of 9,000 simulations: 2 dispersal abilities $\times 3$ niche breadths $\times 3$ climate scenarios $\times 500$ seed points. Each simulation was run for 150,000 time steps after the burn-in period of 50,000 time steps. This time period equates to 1.5 climate cycles under the slow scenario, 3 cycles under the moderate scenario, and 6 cycles under the rapid scenario. The three climate scenarios were used to test whether niche breadth and dispersal ability dynamics were congruent across different rates and periodicities of climate change. Simulations were conducted in $\mathrm{C}++$ and controlled by a master-agent-slave framework (sensu Schimkat et al. 2000) in Java.

In summary, the simulations operate as follows: $G(t)$ is a vector of zeros and ones representing the occupied cells at time $t . \mathbf{M}$ is a matrix representing the dispersal properties of the species across the landscape and indicates cells that can be reached from other cells in one time step. $\mathbf{M}$ is determined by the dispersal ability of the species and is invariant through time. Finally, a diagonal matrix $\mathbf{N}(t)$ calculates the difference between the environment in the $i$ th cell and the niche center of the species. If the difference is less than a threshold value determined by the species' niche breadth, the cell is suitable for the species. Beginning with a historically set initial distribution $G(0)$, two operations occur: dispersal $\mathbf{M} \times G(0)$ and assessment of cell suitability $\mathbf{N}(t) \times \mathbf{M} \times G(0)$. These steps establish the next state of the system as $G(t+1) \leftarrow \mathbf{N}(t) \times \mathbf{M} \times G(t)$. This process is iterated over 200,000 time steps ( $=$ burn-in $+150,000$ steps of changing climate), where $\mathbf{N}(t)$ changes as a function of changing climate. The framework, therefore, is a forced system.

\section{Data Analysis}

In light of the multivariate nature of our predictions, we examined effects of climate scenario, niche breadth, and dispersal ability on counts of speciation and extinction events independently, using a generalized linear model (GLM) assuming a Poisson distribution of errors and a logit link function. We also assessed influences of niche breadth and dispersal ability on speciation and extinction separately within each climate-change scenario. Analyses were conducted in Statistica, version 12 (StatSoft). 
We used hierarchical partitioning (Chevan and Sutherland 1991) to identify the most likely explanatory factors in the model while minimizing influences of multicollinearity. This approach provides a measure of the effect strength of each factor that is largely independent of effects of other factors (Chevan and Sutherland 1991; Mac Nally 2002). Analyses were performed on the full data set as well as individually for the three climate-change scenarios. Statistical significance of independent contributions of the variables was tested using a randomization routine. These analyses were implemented in the hier.part package of R (Mac Nally and Walsh 2004).

\section{Results}

Computational limitations prevented some simulations from processing to the full 200,000 time steps; these partial runs $(1,242$ of 9,000) were removed from our analyses (see summary in tables A1, A2; tables A1-A5, S1 available online). Of the 18 macroecological and climate combinations, 14 were characterized by more than 400 of the 500 simulations, and all combinations had more than 190 simulations completea number that is more than adequate to assess diversification dynamics statistically. Although no systematic bias was identified (tables A1, A2), scenarios with good dispersers failed more because they required more computational power (i.e., species could search and occupy larger spatial extents, which necessitated more memory to store distributions and more processing power to simulate change through time).

Speciation and extinction events were tabulated across the 7,758 simulations for each of the 18 simulation combinations (raw output provided in supplementary table S1). Overall, the simulations averaged 94 speciation events but only one extinction event per simulation. Note that this imbalance between numbers of speciation and extinction events did not affect our results since each process was analyzed and interpreted independently.

Assessing relationships between speciation rates and climate scenario, niche breadth, and dispersal ability (table A3), all three predictors and their interactions had significant impacts on speciation events $(P<.001)$. The proportional difference in deviance explained by this model and a simple null model $(\mathrm{Y} \sim 1)$ was $29.6 \%$, which is statistically significant $(P<.001)$. Highest numbers of speciation events were observed under faster rates of climate change for species with narrow niches and poor dispersal abilities. When the multivariate analysis was repeated for each climate scenario independently, niche breadth, dispersal ability, and their interaction continued to have significant effects on rates of speciation $(P<.0001$ in all analyses; fig. 3; table A4).

Analyzing the entire data set, climate scenario, niche breadth, dispersal ability, and their interactions also contributed significantly to numbers of extinction events (ta- ble A3). Contrary to the patterns observed for speciation, however, the highest numbers of extinction events were observed for good-dispersing species under slow climatechange scenarios. Species with narrow niches still experienced more extinctions than those with broad niches. The proportional difference in deviance explained by this GLM analysis and a simple null model $(\mathrm{Y} \sim 1)$ was $13.5 \%$, which is statistically significant $(P<.001)$.

When extinctions were analyzed for each climate-change scenario separately, niche breadth, dispersal ability, and their interaction continued to show significant contributions to extinction counts $(P<.0001$ in all analyses; fig. 3; table A4). Although extinction occurred infrequently, when it did occur within a given simulation, it tended to occur with high magnitude. This pattern likely reflects our strict extinction criteria (i.e., disappearance of all suitable, accessible pixels), lack of biotic interactions, and the oscillatory nature of the climate scenarios.

Hierarchical partitioning applied to the full data set indicated that niche breadth had the strongest independent effect on speciation (40.9\%) when considering all three factors (i.e., climate, niche breadth, dispersal ability; fig. 4). All factors, however, exhibited significant independent effects. In contrast, dispersal produced the strongest independent effect on extinction events (45.5\%), but all factors produced significant independent effects except for niche breadth (fig. 4).

Notably, hierarchical partitioning analyses binned by climate scenario showed congruent patterns between speciation and extinction rates (fig. 5). In both cases, when climate change was slow, dispersal had the strongest independent effect $(57.1 \%$ and $90.7 \%$ for speciation and extinction, respectively). Niche breadth and dispersal ability were significant factors for speciation, whereas only dispersal ability was significant for extinction. Conversely, when rate and periodicity of climate change was fast or moderate, niche breadth had the strongest independent effect: niche breadth contributed $67.4 \%$ and $52.0 \%$ to speciation and $56.3 \%$ and $65.1 \%$ to extinction under fast and moderate climate scenarios, respectively. All factors were significant in these analyses, except for dispersal ability and niche breadth under the fast climate-change scenario as regards extinction (fig. 5). These analyses demonstrate an interesting contrast of species' responses with respect to climate change: under slow change, dispersal has a larger independent effect on speciation and extinction events, whereas under fast change, niche breadth affects diversification more strongly.

\section{Discussion}

Because biological diversification is a broadscale, multifaceted phenomenon that has occurred over the course of millions of years, it has remained a challenge to quantitative 

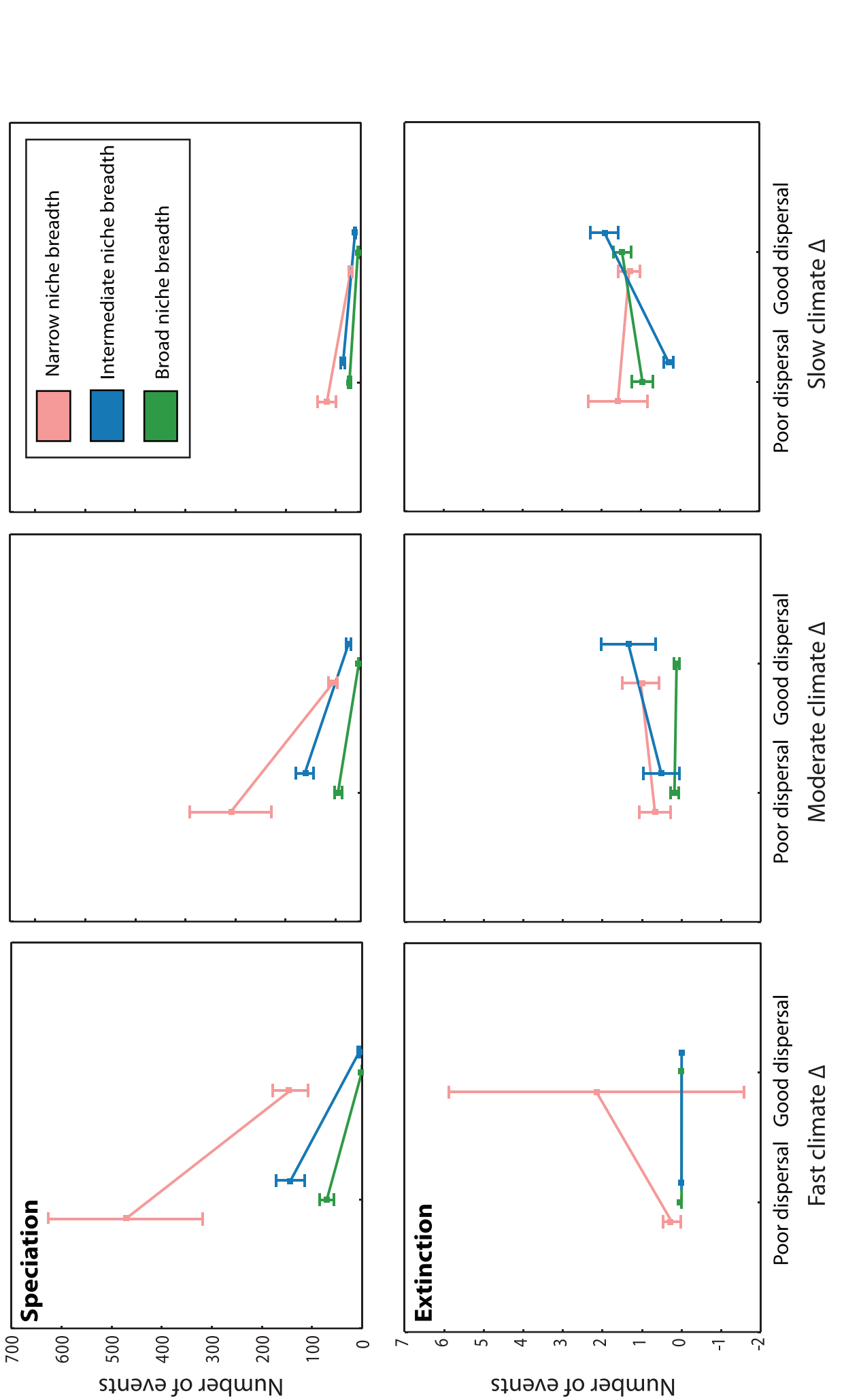

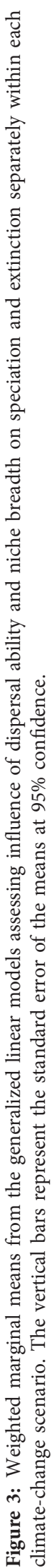

This content downloaded from 129.237.046.008 on December 11, 2017 09:29:14 AM All use subject to University of Chicago Press Terms and Conditions (http://www.journals.uchicago.edu/t-and-c). 

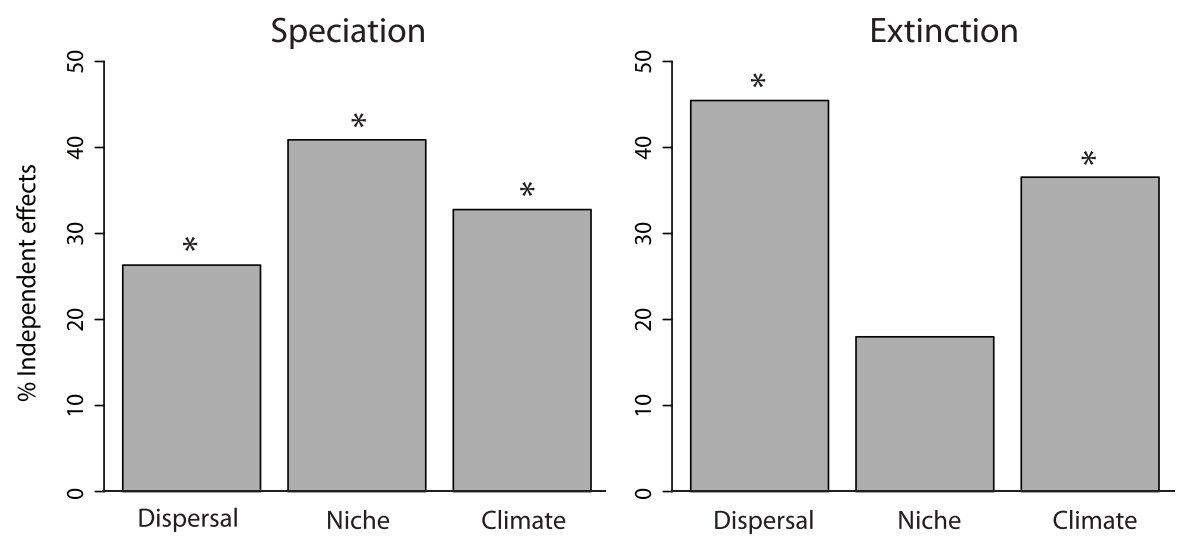

Figure 4: Hierarchical partitioning analyses showing independent effects of niche breadth, dispersal ability, and climate-change scenario on patterns of speciation and extinction, expressed as percentages of total variance explained. All simulation data (i.e., 7,758 runs) were analyzed together. Asterisks denote significance under a criterion of $\alpha=0.05$.

analysis and opaque to experimentation. Our simulations assessed impacts of niche breadth and dispersal ability on diversification under different scenarios of climate change. Importantly, these simulations are not equivalent to empirical investigation but rather represent experiments that enable specific exploration of how species' abiotic tolerances and dispersal abilities interact with a dynamic climate system in a world that is geographically structured. The goal of this study was to compare and contrast plausible ecologyclimate interactions and to observe their effects on diversification.

As in all models, ours does not reflect every aspect of biological reality. Instead, these simulations follow the dynamics of simplified species and environments: no evolutionary change occurs, no interactions exist between species, suitable habitat is dictated solely by two environmental factors, and climate change is episodic and predictable. Consequently, all species' niches are potentially broader than what exists in nature, and their occupation of suitable abiotic habitat may be more complete for lack of biotic constraints such as competition. These simplifications, however, are unlikely to impact our results significantly, since the goal was a relative comparison of extremes. That is, so long as the narrow versus broad niche breadth and the good versus poor dispersal ability were sufficiently different, then understanding how these traits interact with each other and changing climate conditions is both interesting and valuable for guiding development of testable hypotheses using empirical data.

We purposely used simplified species traits and environmental change to provide generalizable predictions. In the course of the study, we identified several ways in which a next generation of this model may be improved. Currently, our simulations are limited to Eurasia, which contains some biogeographically unique features (e.g., Eurasia has several major east-west-oriented mountain ranges, whereas mountain systems elsewhere are often oriented north-south). Major biogeographic barriers limit dispersal of species in specific ways, which is likely to impact macroevolutionary patterns in a manner that is context specific. Furthermore, regional environments may change nonuniformly and nonlinearly with latitude (Bromwich et al. 2013; Pachauri et al. 2014). Applying more complex models of climate change, such as a continuous (transitory) climate model throughout the Pleistocene, will better estimate conditions for specific regions independently. Our simulations can also be made more realistic by allowing niche evolution and by including biotic interactions to limit occupation of the landscape (e.g., competition could be invoked by preventing multiple species from occupying a single pixel). Expansion of our simulations to a global extent using a more realistic model of climate change and incorporating niche evolution and biotic limitations is currently under way.

Within the current framework, however, we were able to isolate the effects of specific macroecological traits on diversification. We observed that both niche breadth and dispersal ability influenced speciation and extinction rates under a suite of dynamic climate scenarios. The effect on diversification was positive, with higher numbers of speciation events occurring with more rapid climate change. These results are congruent with patterns observed over geologic history, where these traits have structured macroevolution; for example, elevated turnover rates are observed during periods of more rapid environmental change (Eldredge and Gould 1972; Vrba and Eldredge 1984; Barnosky and Kraatz 2007; Erwin 2009; Myers and Saupe 2013).

Our simulations returned limited numbers of extinctions compared to speciations, which may reflect an extinction criterion that was overly strict. This strict criterion was chosen purposefully in keeping with our goals of simplifying 


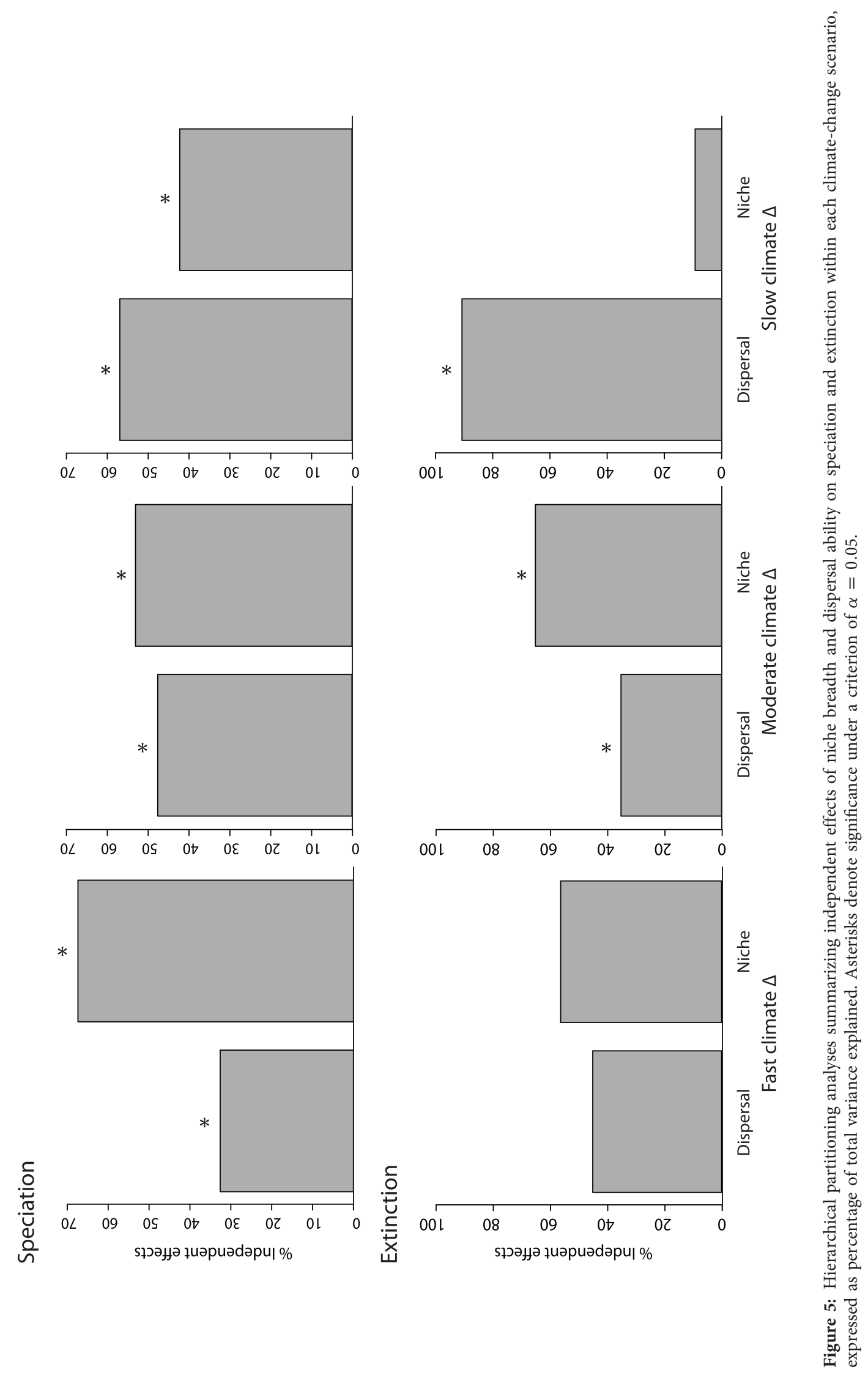

This content downloaded from 129.237.046.008 on December 11, 2017 09:29:14 AM 
reality and exploring generalizable results from extreme conditions. The low numbers of extinctions under these conditions is interesting, however, in that it supports the prediction that extinction rates in nature are not structured by loss of suitable habitat alone (Martínez-Meyer et al. 2004; O'Grady et al. 2004; Mace et al. 2008; Harnik 2011; Harnik et al. 2012b; Saupe et al. 2015). Additional factors - such as population-size thresholds, Allee effects, biotic interactions, or random stochastic events - may, therefore, play an important role in structuring empirical patterns of extinction.

Alternatively, extinctions may be less common in our simulations as a result of the simplified climate curves used. That is, low extinction rates may be caused by climate change that is too smooth and/or not sufficiently extreme, resulting in maintenance of suitable, accessible habitats for a given species at most times (Cooper et al. 2015). From this perspective, our environmental landscape acts as a cradle of diversification, where frequent habitat fragmentation promotes speciation but few species are eliminated. Low extinction also acts to increase speciation rates, since a larger species pool survives to produce even more species through time.

We initially predicted a primary role for niche breadth and a secondary role for dispersal ability in controlling patterns of speciation and extinction. Interestingly, this prediction was supported under rapid and moderate climatechange scenarios but not under the slow climate-change scenario, in which dispersal ability contributed more to diversification. Consequently, our prediction that climate scenario would not significantly impact how species' macroecological traits interact to produce speciations and extinctions was firmly rejected. Conceptually, these results make sense: when climate is changing rapidly, a species may not have sufficient time to track suitable conditions, regardless of how far afield it can search, such that a species' ability to survive within the new environmental conditions will dictate patterns of speciation and extinction more strongly than dispersal ability. In contrast, under slow climate change, species may have sufficient time to track suitable habitats and, thus, the ability to find and disperse to suitable conditions may influence diversification rates more significantly.

Thus, even within a model system, the influence of macroecological traits on diversification appears to be dependent on rates of environmental change. This linkage has important implications for informing predictions of how real species may respond to current and future conditions. Modifications to climate and ocean systems are now occurring at a rate that is twice that estimated for environmental changes associated with most historical mass extinctions (Barnosky et al. 2011; Harnik et al. 2012a; Pimm et al. 2014; Finnegan et al. 2015). Such rapid change suggests that the important trait to consider in current conservation is likely niche breadth: species with narrow niches may prove to be most vulnerable to environmental changes.
Regarding speciation, although the relative importance of those traits affecting diversification differed depending on the rate of climate change, the directionality of that influence remained similar under the different climate scenarios. That is to say, we found the predicted inverse relationship between dispersal ability and niche breadth and their effects on speciation rates for all climate scenarios. The directionality of how these traits influenced extinction was more complex; as anticipated, niche breadth had an inverse relationship with extinction rates if assessed across climate scenarios but dispersal ability did not. In our simulations, extinctions occurred more often in species that were good dispersers. This may reflect an increased ability for good dispersers to establish ephemeral, peripherally distributed populations that persisted long enough to speciate but were nonetheless more susceptible to extinction when the environment changed. Species with poor dispersal abilities do not show this pattern because they were not able to access such far-flung, transient suitable habitats. Importantly, if we consider only those scenarios that experienced $>0$ extinction, we obtain the expected pattern of poor dispersers experiencing more extinction (table A5).

In conclusion, our simulations determine that, under a set of simple processes and assumptions, niche breadth and dispersal both influence biological diversity, and these effects can vary under different rates of environmental change (Allmon and Ross 1990; Allmon et al. 1998; Lieberman 2012). Previous investigations have used simulation studies to understand patterns of species richness (e.g., Rangel et al. 2007; Gotelli et al. 2009; Colwell and Rangel 2010; Nakazawa 2013; Nakazawa and Peterson 2015). Such studies, however, have not unpacked the influence of multiple macroecological traits on the suite of factors that drive diversification. Most likely, important differences exist among traits that impact speciation and extinction potential versus those that control patterns of species richness and community assembly (e.g., the latter may require assumptions and/ or models of biotic interactions). We have provided a novel analysis that investigates explicitly the influences of macroecological traits on species' macroevolutionary trajectories given a dynamic climate system; the result is a more nuanced understanding of the potential influence of environmental change in the generation and maintenance of diversity and a rich source of ideas for empirical testing.

\section{Acknowledgments}

We thank A. Algar, J. Bronstein, D. Collar, and an anonymous reviewer for helpful comments and suggestions that improved the quality of the article. Many thanks to the Lieberman Lab and the University of Kansas Ecological Niche Modeling group for discussions that generated the initial ideas for this project. We thank A. Knoll for thought- 
ful comments on an early version of the manuscript. E.E.S. was supported by a National Science Foundation (NSF) GK-12 Graduate Fellowship and the Yale Institute for Biospheric Studies. C.E.M. was supported by the NASA Astrobiology Institute Postdoctoral Program, Harvard University, and the University of New Mexico. J.S. was partially supported by NSF grant 1208472 .

\section{Literature Cited}

Allen, A. P., and J. F. Gillooly. 2006. Assessing latitudinal gradients in speciation rates and biodiversity at the global scale. Ecology Letters 9:947-954.

Allmon, W. D., P. J. Morris, and M. L. McKinney. 1998. An intermediate disturbance hypothesis of maximal speciation. Pages 349376 in M. L. McKinney and J. A. Drake, eds. Biodiversity dynamics: turnover of populations, taxa, and communities. Columbia University Press, New York.

Allmon, W. D., and R. M. Ross, eds. 1990. Specifying causal factors in evolution: the paleontological contribution. Pages 1-17 in Causes of evolution: a paleontological perspective. University of Chicago Press, Chicago.

Barnosky, A. D., and B. P. Kraatz. 2007. The role of climatic change in the evolution of mammals. Bioscience 57:523-532.

Barnosky, A. D., N. Matzke, S. Tomiya, G. O. Wogan, B. Swartz, T. B. Quental, C. Marshall, et al. 2011. Has the Earth's sixth mass extinction already arrived? Nature 471:51-57.

Barraclough, T. G., and A. P. Vogler. 2000. Detecting the geographical pattern of speciation from species-level phylogenies. American Naturalist 155:419-434.

Bromwich, D. H., J. P. Nicolas, A. J. Monaghan, M. A. Lazzara, L. M. Keller, G. A. Weidner, and A. B. Wilson. 2013. Central West Antarctica among the most rapidly warming regions on Earth. Nature Geoscience 6:139-145.

Bullock, J. M., R. J. Edwards, P. D. Carey, and R. J. Rose. 2000. Geographical separation of two Ulex species at three spatial scales: does competition limit species' ranges? Ecography 23:257-271.

Cain, M. L., B. G. Milligan, and A. E. Strand. 2000. Long-distance seed dispersal in plant populations. American Journal of Botany 87:1217-1227.

Chevan, A., and M. Sutherland. 1991. Hierarchical partitioning. American Statistician 45:90-96.

Chown, S. L., and K. J. Gaston. 2000. Areas, cradles and museums: the latitudinal gradient in species richness. Trends in Ecology and Evolution 15:311-315.

Colwell, R. K., and T. F. Rangel. 2010. A stochastic, evolutionary model for range shifts and richness on tropical elevational gradients under Quaternary glacial cycles. Philosophical Transactions of the Roval Societv B: Biological Sciences 365:3695-3707.

Cooper, A., C. Turney, K. A. Hughen, B. W. Brook, H. G. McDonald, and C. J. Bradshaw. 2015. Abrupt warming events drove Late Pleistocene Holarctic megafaunal turnover. Science 349:602-606.

Dieckmann, U., B. O'Hara, and W. Weisser. 1999. The evolutionary ecology of dispersal. Trends in Ecology and Evolution 14:88-90.

Diniz-Filho, J. A. F., and N. M. Tôrres. 2002. Phylogenetic comparative methods and the geographic range size-body size relationship in New World terrestrial carnivora. Evolutionary Ecology 16: 351-367.
Dobrovolski, R., A. S. Melo, F. A. Cassemiro, and J. A. F. DinizFilho. 2012. Climatic history and dispersal ability explain the relative importance of turnover and nestedness components of beta diversity. Global Ecology and Biogeography 21:191-197.

Eastman, J. M., and A. Storfer. 2011. Correlations of life-history and distributional-range variation with salamander diversification rates: evidence for species selection. Svstematic Biology 60:503-518.

Edwards, D. L., J. S. Keogh, and L. L. Knowles. 2012. Effects of vicariant barriers, habitat stability, population isolation and environmental features on species divergence in the south-western Australian coastal reptile community. Molecular Ecology 21:3809-3822.

Eldredge, N. 1979. Alternative approaches to evolutionary theory. Bulletin of the Carnegie Museum of Natural History 13:7-19.

-1989. Macroevolutionary dynamics: species, niches, and adaptive peaks. McGraw Hill, New York.

. 2003. The sloshing bucket: how the physical realm controls evolution. Pages 3-32 in J. P. Crutchfield and P. Schuster, eds. Evolutionary dynamics: exploring the interplay of selection, accident, neutrality, and function. Oxford University Press, New York.

Eldredge, N., and S. J. Gould. 1972. Punctuated equilibria: an alternative to phyletic gradualism. Pages $82-115$ in T. J. M. Schopf, ed. Models in paleobiology. Freeman Cooper, San Francisco.

Erwin, D. H. 2009. Climate as a driver of evolutionary change. Current Biology 19:R575-R583.

Escarguel, G., A. Brayard, and H. Bucher. 2008. Evolutionary rates do not drive latitudinal diversity gradients. Iournal of Zoological Systematics and Evolutionary Research 46:82-86.

Finnegan, S., S. C. Anderson, P. G. Harnik, C. Simpson, D. P. Tittensor, J. E. Byrnes, Z. V. Finkel, et al. 2015. Paleontological baselines for evaluating extinction risk in the modern oceans. $\underline{\text { Sci- }}$ ence 348:567-570.

Fisher-Reid, M. C., K. H. Kozak, and J. J. Wiens. 2012. How is the rate of climatic-niche evolution related to climatic-niche breadth? Evolution 66:3836-3851.

Fitzpatrick, B. M., J. A. Fordyce, and S. Gavrilets. 2009. Pattern, process and geographic modes of speciation. Iournal of Evolutionary Biology 22:2342-2347.

Gaston, K. J. 2003. The structure and dynamics of geographic ranges. Oxford University Press, New York.

Gilbert, B., and M. J. Lechowicz. 2004. Neutrality, niches, and dispersal in a temperate forest understory. Proceedings of the National Academv of Sciences of the USA 101:7651-7656.

Gili, C., and J. Martinell. 1994. Relationship between species longevity and larval ecology in nassariid gastropods. Lethaia 27: 291-299.

Gotelli, N. J., M. J. Anderson, H. T. Arita, A. Chao, R. K. Colwell, S. R. Connolly, D. J. Currie, et al. 2009. Patterns and causes of species richness: a general simulation model for macroecology. Ecology Letters 12:873-886.

Gould, S. J. 2002. The structure of evolutionary theory. Harvard University Press, Cambridge, MA.

Grimm, V., E. Revilla, U. Berger, F. Jeltsch, W. M. Mooij, S. F. Railsback, H.-H. Thulke, J. Weiner, T. Wiegand, and D. L. DeAngelis. 2005. Pattern-oriented modeling of agent-based complex systems: lessons from ecology. Science 310:987-991.

Hansen, T. A. 1980. Influence of larval dispersal and geographic distribution on species longevity in neogastropods. Paleobiology 6: 193-207.

-1983. Modes of larval development and rates of speciation in early Tertiary neogastropods. Science 220:501-502. 
Harnik, P. G. 2011. Direct and indirect effects of biological factors on extinction risk in fossil bivalves. Proceedings of the National Academv of Sciences of the USA 108:13594-13599.

Harnik, P. G., H. K. Lotze, S. C. Anderson, Z. V. Finkel, S. Finnegan, D. R. Lindberg, L. H. Liow, et al. 2012a. Extinctions in ancient and modern seas. Trends in Ecology and Evolution 27:608-617.

Harnik, P. G., C. Simpson, and J. L. Payne. 2012b. Long-term differences in extinction risk among the seven forms of rarity. Proceedings of the Roval Societv B: Biological Sciences 279:4969-4976.

Harris, G., and S. L. Pimm. 2008. Range size and extinction risk in forest birds. Conservation Biology 22:163-171.

Hijmans, R. J., S. E. Cameron, J. L. Parra, P. G. Jones, and A. Jarvis. 2005. Very high resolution interpolated climate surfaces for global land areas. International Journal of Climatology 25:1965-1978.

Hijmans, R., L. Guarino, M. Cruz, and E. Rojas. 2001. Computer tools for spatial analysis of plant genetic resources data: 1. DIVAGIS. Plant Genetic Resources Newsletter 127:15-19.

Hooten, M. B., and C. K. Wikle. 2010. Statistical agent-based models for discrete spatio-temporal systems. Journal of the American Statistical Association 105:236-248.

Hutchinson, G. E. 1957. Concluding remarks. Cold Spring Harbor Svmposium on Quantitative Biology 22:415-427.

Jablonski, D. 1986. Larval ecology and macroevolution in marine invertebrates. Bulletin of Marine Science 39:565-587.

- 2008. Extinction and the spatial dynamics of biodiversity. Proceedings of the National Academy of Sciences of the USA 105:11528-11535.

Jackson, S. T., and J. T. Overpeck. 2000. Responses of plant populations and communities to environmental changes of the late Quaternary. Paleobiology 26:194-220.

Johnson, N. K., and C. Cicero. 2004. New mitochondrial DNA data affirm the importance of Pleistocene speciation in North American birds. Evolution 58:1122-1130.

Kammer, T. W., T. K. Baumiller, and W. I. Ausich. 1997. Species longevity as a function of niche breadth: evidence from fossil crinoids. Geology 25:219-222.

1998. Evolutionary significance of differential species longevity in Osagean-Meramecian (Mississippian) crinoid clades. Paleobiology 24:155-176.

Kisel, Y., and T. G. Barraclough. 2010. Speciation has a spatial scale that depends on levels of gene flow. American Naturalist 175:316334.

Knowles, L. L. 2000. Tests of Pleistocene speciation in montane grasshoppers (genus Melanoplus) from the sky islands of western North America. Evolution 54:1337-1348.

Knowles, L. L., and D. F. Alvarado-Serrano. 2010. Exploring the population genetic consequences of the colonization process with spatio-temporally explicit models: insights from coupled ecological, demographic and genetic models in montane grasshoppers. Molecular Ecology 19:3727-3745.

Lande, R. 1980. Genetic variation and phenotypic evolution during allopatric speciation. American Naturalist 116:463-479.

Lester, S. E., B. I. Ruttenberg, S. D. Gaines, and B. P. Kinlan. 2007. The relationship between dispersal ability and geographic range size. Ecology Letters 10:745-758.

Lieberman, B. S. 2005. Earth history change: the pacemaker of evolution. Paleontological Society Papers 11:5-13.

2012. Adaptive radiations in the context of macroevolutionary theory: a paleontological perspective. Evolutionary Biology 39: $181-191$.
Lieberman, B. S., W. D. Allmon, and N. Eldredge. 1993. Levels of selection and macroevolutionary patterns in the turritellid gastropods. Paleobiology 19:205-215.

Linder, H. P., D. L. Rabosky, A. Antonelli, R. O. Wüest, and R. Ohlemüller. 2014. Disentangling the influence of climatic and geological changes on species radiations. Lournal of Biogeography 41:1313-1325.

Liow, L. H., and N. C. Stenseth. 2007. The rise and fall of species: implications for macroevolutionary and macroecological studies. Proceedings of the Roval Societv B: Biological Sciences 274:2745-2752.

Mace, G. M., N. J. Collar, K. J. Gaston, C. Hilton-Taylor, H. R. Akçakaya, N. Leader-Williams, E. J. Milner-Gulland, and S. N. Stuart. 2008. Quantification of extinction risk: IUCN's system for classifying threatened species. Conservation Biology 22:1424-1444.

Mac Nally, R. 2002. Multiple regression and inference in ecology and conservation biology: further comments on identifying important predictor variables. Biodiversity and Conservation 11:1397-1401.

Mac Nally, R., and C. Walsh. 2004. Hierarchical partitioning publicdomain software. Biodiversity and Conservation 13:659-660.

Martínez-Meyer, E., A. Townsend Peterson, and W. W. Hargrove. 2004. Ecological niches as stable distributional constraints on mammal species, with implications for Pleistocene extinctions and climate change projections for biodiversity. Global Ecology and Biogeography 13:305-314.

Mayr, E. 1942. Systematics and the origin of species. Oxford University Press, New York.

Myers, C. E., and E. E. Saupe. 2013. A macroevolutionary expansion of the modern synthesis and the importance of extrinsic abiotic factors. Palaeontology 56:1179-1198.

Nakazawa, Y. 2013. Niche breadth, environmental landscape, and physical barriers: their importance as determinants of species distributions. Biological Journal of the Linnean Society 108:241-250.

Nakazawa, Y., and A. T. Peterson. 2015. Effects of climate history and environmental grain on species' distributions in Africa and South America. Biotropica 47:292-299.

Nürnberg, S., and M. Aberhan. 2013. Habitat breadth and geographic range predict diversity dynamics in marine Mesozoic bivalves. $\mathrm{Pa}$ leobiology 39:360-372

O'Grady, J. J., D. H. Reed, B. W. Brook, and R. Frankham. 2004. What are the best correlates of predicted extinction risk? Biological Conservation 118:513-520.

Pachauri, R. K., M. Allen, V. Barros, J. Broome, W. Cramer, R. Christ, J. Church, et al. 2014. Climate Change 2014: Synthesis Report. Contribution of Working Groups I, II and III to the Fifth Assessment Report of the Intergovernmental Panel on Climate Change, 151 pages. IPCC, Geneva.

Palumbi, S. R. 1994. Genetic divergence, reproductive isolation, and marine speciation. Annual Review of Ecology and Systematics 25: 547-572.

Peterson, A. T., J. Soberón, R. G. Pearson, R. P. Anderson, E. Martínez-Meyer, M. Nakamura, and M. B. Araújo. 2011. Ecological niches and geographic distributions. Princeton University Press, Princeton, NJ.

Pimm, S. L., C. N. Jenkins, R. Abell, T. M. Brooks, J. L. Gittleman, L. N. Joppa, P. H. Raven, C. M. Roberts, and J. O. Sexton. 2014. The biodiversity of species and their rates of extinction, distribution, and protection. Science 344, doi:10.1126/science.1246752.

Rangel, T. F. L. V. B., and J. A. F. Diniz-Filho. 2005. Neutral community dynamics, the mid-domain effect and spatial patterns in species richness. Ecology Letters 8:783-790. 
Rangel, T. F. L. V. B., J. A. F. Diniz-Filho, and R. K. Colwell. 2007. Species richness and evolutionary niche dynamics: a spatial patternoriented simulation experiment. American Naturalist 170:602-616.

Rothschild, L., and A. Lister. 2003. Evolution on planet earth: impact of the physical environment. Academic Press, London.

Roy, K., and E. E. Goldberg. 2007. Origination, extinction, and dispersal: integrative models for understanding present-day diversity gradients. American Naturalist 170(suppl.):S71-S85.

Salisbury, C. L., N. Seddon, C. R. Cooney, and J. A. Tobias. 2012. The latitudinal gradient in dispersal constraints: ecological specialisation drives diversification in tropical birds. Ecology Letters 15: 847-855.

Saupe, E. E., V. Barve, C. E. Myers, J. Soberón, N. Barve, C. M. Hensz, A. T. Peterson, H. L. Owens, and A. Lira-Noriega. 2012. Variation in niche and distribution model performance: the need for a priori assessment of key causal factors. Ecological Modelling 237:11-22.

Saupe, E. E., H. Qiao, J. R. Hendricks, R. W. Portell, S. J. Hunter, J. Soberón, and B. S. Lieberman. 2015. Niche breadth and geographic range size as determinants of species survival on geological time scales. Global Ecology and Biogeography 24:1159-1169.

Schimkat, R.-D., W. Blochinger, C. Sinz, M. Friedrich, and W. Küchlin. 2000. A service-based agent framework for distributed symbolic computation. Pages 644-656 in M. Bubak, H. Afsarmanesh, B. Hertzberger, and R. Williams, eds. Proceedings of the 8th International Conference on High Performance Computing and Networking Europe (HPCN '00). Lecture Notes in Computer Science. Springer LNCS, Amsterdam.

Shuto, T. 1974. Larval ecology of prosobranch gastropods and its bearing on biogeography and paleontology. Lethaia 7:239-256.

Soberón, J. 2007. Grinnellian and Eltonian niches and geographic distributions of species. Ecology Letters 10:1115-1123.

Soberón, J., and A. T. Peterson. 2005. Interpretation of models of fundamental ecological niches and species' distributional areas. Biodiversity Informatics 2:1-10.

Soberón, J. M. 2010. Niche and area of distribution modeling: a population ecology perspective. Ecography 33:159-167.

Stanley, S. M. 1990. The general correlation between rate of speciation and rate of extinction: fortuitous causal linkages. Pages 103127 in R. M. Ross and W. D. Allmon, eds. Causes of evolution: a paleontological perspective. University of Chicago Press, Chicago.
Svenning, J. C., W. L. Eiserhardt, S. Normand, A. Ordonez, and B. Sandel. 2015. The influence of paleoclimate on present-day patterns in biodiversity and ecosystems. Annual Review of Ecology. Evolution, and Systematics 46:551-572.

Svenning, J. C., and B. Sandel. 2013. Disequilibrium vegetation dynamics under future climate change. American Journal of Botany 100:1266-1286.

Turelli, M., N. H. Barton, and J. A. Coyne. 2001. Theory and speciation. Trends in Ecology and Evolution 16:330-343.

Valentine, J. W. 1985. Biotic diversity and clade diversity. Pages 419424 in J. W. Valentine, ed. Phanerozoic Diversity Patterns. Princeton University Press, Princeton, NJ.

Vrba, E. S. 1980. Evolution, species and fossils: how does life evolve. South African Journal of Science 76:61-84.

1985. Environment and evolution: alternative causes of the temporal distribution of evolutionary events. South African Journal of Science 81:229-236.

Vrba, E. S., and N. Eldredge. 1984. Individuals, hierarchies and processes: towards a more complete evolutionary theory. Paleobiology 10:146-171.

Webb, T. J., and K. J. Gaston. 2000. Geographic range size and evolutionary age in birds. Proceedings of the Roval Society B: Biological Sciences 267:1843-1850.

Wiens, J. J., and M. J. Donoghue. 2004. Historical biogeography, ecology and species richness. Trends in Ecology and Evolution 19: 639-644.

Wiley, E. O., and B. S. Lieberman. 2011. Phylogenetics: theory and practice of phylogenetic systematics. J. Wiley \& Sons, Hoboken, NJ.

Williamson, P. G. 1981. Palaeontological documentation of speciation in Cenozoic molluscs from Turkana Basin. Nature 293:437-443.

Wisz, M. S., J. Pottier, W. D. Kissling, L. Pellissier, J. Lenoir, C. F. Damgaard, C. F. Dormann, et al. 2013. The role of biotic interactions in shaping distributions and realised assemblages of species: implications for species distribution modelling. Biological Reviews 88:15-30.

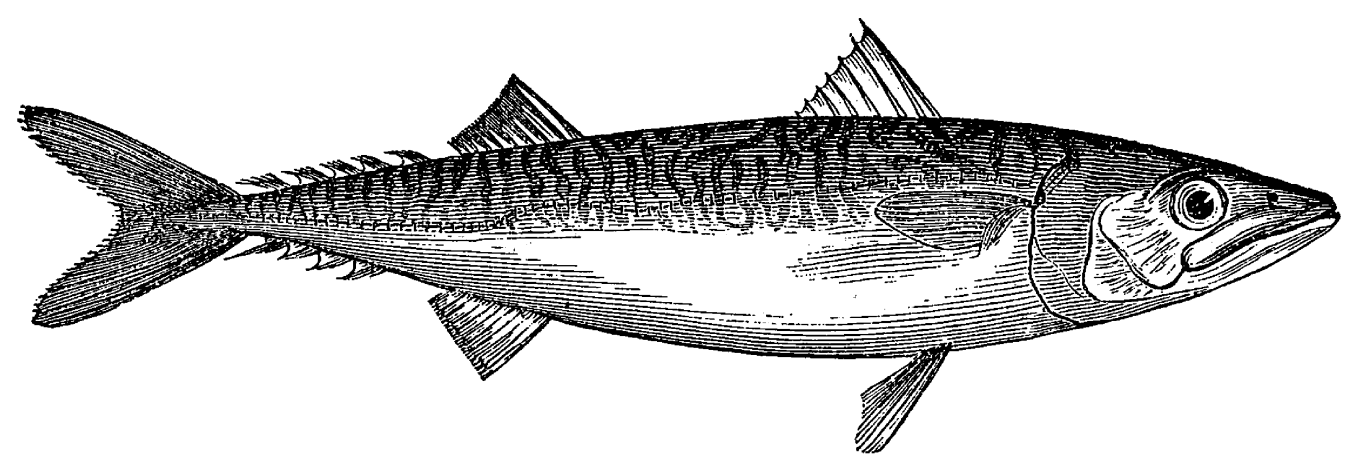

"The Mackerel (Scomber vernalis) ... approach the coast for the purpose of spawning, and on reaching a favorable situation, immediately deposit their eggs, and leave them without farther protection. The number of eggs deposited in one season by each female is estimated to be between five and six hundred thousand." From "The Habits and Migrations of Some of the Marine Fishes of Massachusetts" by James H. Blake (The American Naturalist, 1870, 4:513-521). 